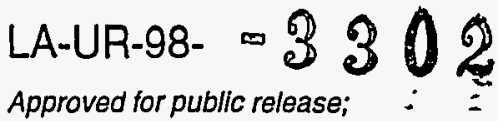 distribution is unlimited
}

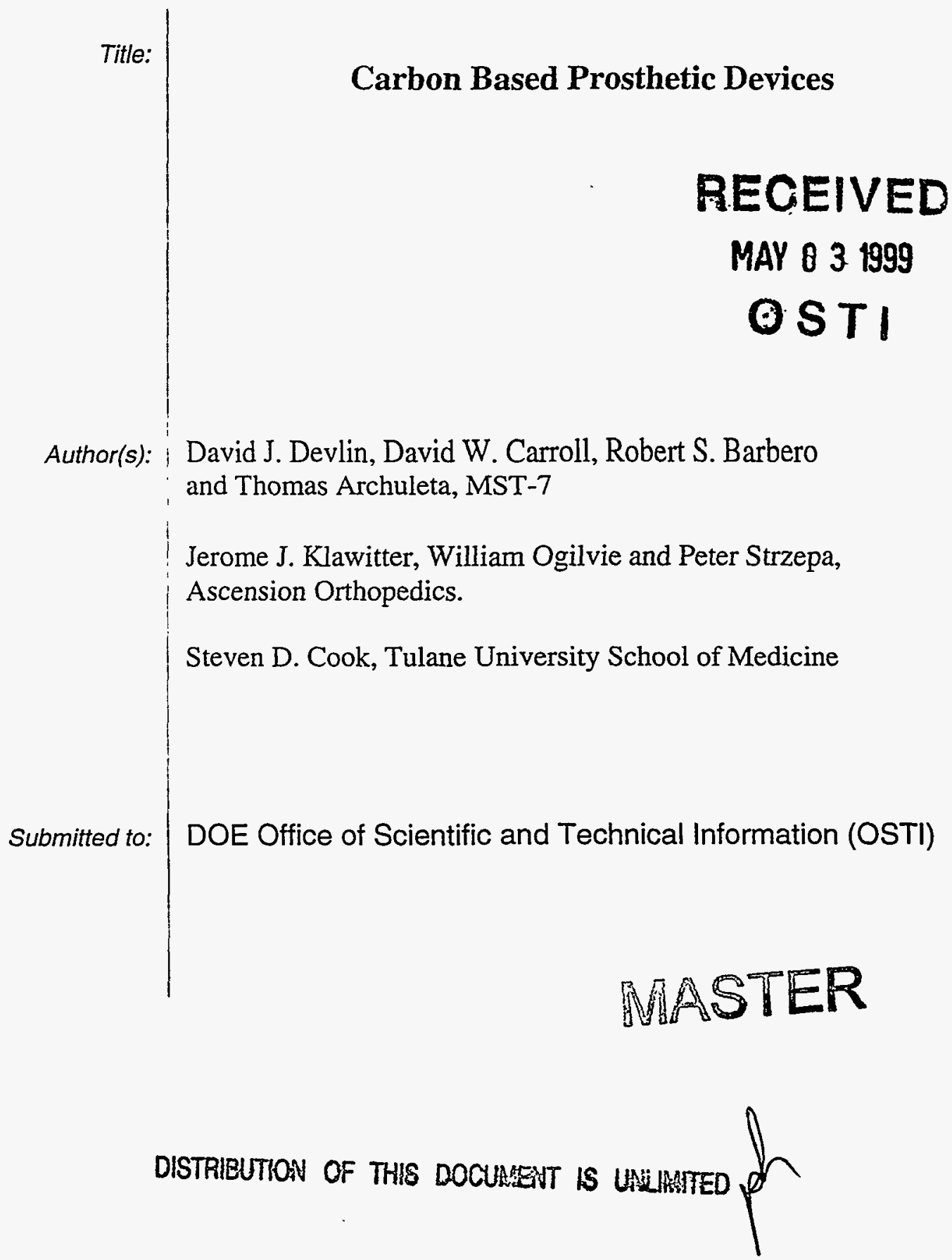

\section{Los Alamos}

NATIONAL LABORATORY

Los Alamos National Laboratory, an affirmative action/equal opportunity employer, is operated by the University of California for the U.S. Department of Energy under contract W-7405-ENG-36. By acceptance of this article, the publisher recognizes that the U.S. Govemment retains a nonexclusive, royaltytree license to publish or reproduce the published form of this contribution, or to allow others to do so, for U.S. Govemment purposes. Los Alamos National Laboratory requests that the publisher identify this article as work performed under the auspices of the U.S. Department of Energy. Los Alamos Nationa! Laboratory strongly supports academic freedom and a researcher's right to publish; as an institution, however, the Laboratory does not endorse the viewpoint of a publication or guarantee its technical correctness. 


\section{DISCLAIMER}

This report was prepared as an account of work sponsored by an agency of the United States Government. Neither the United States Government nor any agency thereof, nor any of their employees, makes any warranty, express or implied, or assumes any legal liability or responsibility for the accuracy, completeness, or usefulness of any information, apparatus, product, or process disclosed, or represents that its use would not infringe privately owned rights. Reference herein to any specific commercial product, process, or service by trade name, trademark, manufacturer, or otherwise does not necessarily constitute or imply its endorsement, recommendation, or favoring by the United States Government or any agency thereof. The views and opinions of authors expressed herein do not necessarily state or reflect those of the United States Government or any agency thereof. 


\section{DISCLAIMER}

Portions of this document may be illegible in electronic image products. Images are produced from the best available original document. 


\title{
Carbon Based Prosthetic Devices
}

\author{
David J. Devlin*, David W. Carroll, Robert S. Barbero and Thomas Archuleta \\ Los Alamos National Laboratory \\ Jerome J. Klawitter, William Ogilvie and Peter Strzepa \\ Ascension Orthopedics \\ Steven D. Cook \\ Tulane University School of Medicine
}

\begin{abstract}
This is the final report of a one-year, Laboratory Directed Research and Development (LDRD) project at the Los Alamos National Laboratory (LANL). The project objective was to evaluate the use of carbon/carbonfiber-reinforced composites for use in endoprosthetic devices. The application of these materials for the metacarpophalangeal (MP) joints of the hand was investigated. Issues concerning mechanical properties, bone fixation, biocompatibility, and wear are discussed. A system consisting of fiber reinforced materials with a pyrolytic carbon matrix and diamond-like, carbon-coated wear surfaces was developed. Processes were developed for the chemical vapor infiltration (CVI) of pyrolytic carbon into porous fiber preforms with the ability to tailor the outer porosity of the device to provide a surface for bone in-growth. A method for coating diamond-like carbon (DLC) on the articulating surface by plasma-assisted chemical vapor deposition (CVD) was developed. Preliminary results on mechanical properties of the composite system are discussed and initial biocompatibility studies were performed.
\end{abstract}

\section{Background and Research Objectives}

The long-term objective of this research is to greatly extend the service life of prosthetic devices, specifically artificial joints. A materials systems approach (the union of two or more materials technologies) was employed to accomplish this objective. These new joints more closely simulate the properties of the actual joint. The two specific materials technologies being integrated in this study are carbon/carbon composites and diamond-like carbon (DLC) coatings. Artificial joints are used to replace joints that are inflicted with diseases or severely injured. These artificial joints are unique mechanicalmaterial systems in that they are exposed to biochemical and dynamic environments of the human body and their design is fixed by anatomy and confined by physiological conditions.

*Principal Investigator, e-mail: ddevlin@lanl.gov 
Critical design elements in these implants include modulus of elasticity, wear resistance, coefficient of friction, corrosion resistance, and biocompatibility with biological tissue and bone. Within these engineering constraints, prosthetic devices must be designed to remain in the body for a lifetime. Metal prostheses, anchored with methyl methacrylate cement, have a useful life of 7 to 10 years. Bond failure necessitates an entire replacement of the prosthesis. Unfortunately, bone resorption due to the presence of the implant limits the number of implant operations to two per patient. As a consequence, joint replacements are restricted to patients over the age of 55 .

Hospital admissions and out-patient data (HCIA In., Baltimore, Md.) indicate that in the 1990s hand surgery implants are used in about 25,000 cases per year in the United States. Medical Data International, Inc. reports (1994, RP-651145) the market potential for digit (small orthopedic joint) implants to be approximately 100,000 units per year in the United States. The Arthritis Foundation estimates there are 40 million individuals suffering from arthritis. This number is expected to reach 60 million by the year 2020 . There are approximately 250,000 hip replacements, an equal number of knee joints, and 400,000 dental implants sold just in the United States each year. The hip and knee joint replacement is a 2 to 3 billion dollar-a-year market. The material developed in this project will be potentially applicable to all of these systems.

The small-joint market consists primarily of replacements for the metacarpophalangeal (MP), proximal interphalangeal (PIP), and carpometacarpal (CMC) joints of the hand and the great toe. The need for implants in the hand and foot arises for the most part from arthritis and trauma, with rheumatoid arthritis being the greatest cause. Rheumatoid arthritis is a disease of the aged and the number of aged individuals continues to increase. Despite the increasing need, the use of small-joint replacement by surgeons worldwide is declining. This reflects the lack of confidence surgeons have in currently available devices. The existing devices for small-joint replacement, of which silicone rubber is the most commonly used, do not meet the surgical needs and are further stigmatized by the silicone breast implant litigation.

Carbon/carbon composite material is known to be biocompatible. In addition, as an implanted device there is evidence of tissue and bone ingrowth. Composites can be customized through fiber reinforcement to provide strength and stiffness in the required directions. Satisfactory fatigue strength and fracture toughness, along with the relatively low density of carbon-carbon composites, combine to make the composite an ideal candidate for prosthetic devices. Diamond-like carbon films exhibit extraordinary wear resistance and coefficient of friction, and display exceptional biocompatibility. A thin layer of DLC on the carbon-carbon composite (head and acetabular cup) would provide ideal 
articulation surfaces of the proposed prosthesis.

Currently stainless steel, cobalt-chromium-molybdenum, and titanium-aluminumvanadium alloys are materials used for the prosthesis stem that anchors into the bone. Bone has a modulus of elasticity ranging from 14 to $28 \mathrm{GPa}$, whereas the moduli for these alloys range between $110 \mathrm{GPa}$ to $300 \mathrm{Gpa}$, resulting in a difference in the moduli of approximately an order of magnitude. Osteoporosis may result from this large mismatch of elasticity between the bone and the implant due to stress shielding [1]. Such bone transformation and degeneration is one of the factors that can promote stem loosening. Following loosening of the stem, the prosthesis ultimately fractures by a fatigue failure mechanism.

The stresses on the femur in walking have been extensively analyzed [2]. It was calculated that the maximum tensile or compressive stresses are approximately 48 to 55 $\mathrm{MPa}$. Carbon/carbon composites exhibit tensile strengths of $138 \mathrm{MPa}$ and compressive strengths of 207 to $276 \mathrm{MPa}$. The femur has a modulus of elasticity ranging from 14 to 28 $\mathrm{GPa}$, compared with 30 to $150 \mathrm{GPa}$ for carbon/carbon composites depending on processing parameters. A femur is composed of various kinds of bone having different properties and is anisotropic in nature. The ability to tailor the composition of the composite prosthesis by directly controlling the properties in three dimensions is essential in order to replicate the actual bone. Carbon/carbon composites have the potential to satisfy this mechanical property challenge. Very little work is presented in the open literature concerning the fatigue performance of carbon/carbon. Carbon/carbon composites demonstrate a lifetime of $10^{7}$ cycles at a stress of $40 \%$ of the static bending strength. A Woeler diagram (stress versus number of load cycles) suggests the material shows a fatigue limit analogous to that of steel. An infinite fatigue life is predicted at $45-50 \%$ of the static strength under cyclic loading. Therefore, the fatigue endurance of carbon/carbon appears to be outstanding.

Wear is found on the articulation surfaces of the prostheses. Currently, the femoral heads are made from either ceramic or metal alloys. The acetabular cups are composed of ultrahigh molecular weight polyethylene. Wear of the articulation surfaces has occasionally been found to be so intense that the components have had to be replaced. The average clinical wear factor derived from measurements on 25 replaced prostheses was $2.9 \times 10^{6}$ $\mathrm{mm}^{3} / \mathrm{Nm}$, with results ranging from $0.09 \times 10^{6}$ to $7.2 \times 10^{6} \mathrm{~mm}^{3} / \mathrm{Nm}$ [3]. Penetration rates of the femoral head into the acetabular cup in current forms of total replacement joints are typically in the range of 0.1 to $0.2 \mathrm{~mm} /$ year. Overall migrations of the head of 2 or $3 \mathrm{~mm}$ is the design limit. These dictate that the wear lives of implants are in the range of 10 to 30 
years. There is increasing concern about the role of wear debris in promoting implant loosening, and consequently there is a need to substantially reduce the volume of wear. DLC films are characterized by extreme hardness that has been measured to be in the range 3000 to $9000 \mathrm{~kg} / \mathrm{mm}^{2}$ [4]. The hardness of DLC is approximately half that of diamond, and consequently DLC could be expected to exhibit exceptional wear resistance. An interesting feature of DLC is the low coefficient of friction $(\approx 0.14$ without any lubrication). DLC has a lower coefficient of friction than the mating components found in present joint prostheses.

Orthopedic implants are exposed to the biomechanical and biochemical forces of the body, and certain interactions take place between the implants and the biological environment. With metal implants low concentrations of metallic ions are released with the possibility of allergic reactions. Additionally, the metallic alloys must be mechanically fastened or anchored with cement such as methyl methacrylate or similar material. Consequently, these materials do not promote bone growth into the implant's surface. Bone ingrowth would provide for superior interfacial strength between the bone and biomaterial that is not observed in existing prosthetic device materials. The biocompatibility of carbon has been demonstrated and has been permitted in the body for many non-load-bearing applications. Heart valves have been produced with isotropic pyrolytic carbon and have been successfully implanted in several hundred thousand patients. Orthopedic pins were coated with DLC and implanted in laboratory animals [5]. The result of the study was that the DLC coating prevented infection of the tissue attached to the pins. Two-dimensional carbon/carbon composites were used as implants in the femurs of rats [6]. The carbon exhibited excellent biocompatibility with the rough surfaces showing a tendency for bone ingrowth. Test results indicated that the carbon/carbon composites provided improved adaptation to bone over titanium implants. Additionally, carbon fibers provided a degradable scaffold on which ligaments can be regenerated [7].

Carbon/carbon composites possess the mechanical and physiological properties essential for use as prostheses, but the optimum structure has not been produced. Composites with $200 \mu \mathrm{m}$-diameter pores would be very favorable for bone ingrowth. Although carbon/carbon composites exhibit good wear characteristics in certain engineering applications (for example brakes), the wear rate and resulting debris may not be acceptable for artificial joints without a protective surface coating. While a significant amount of research has been conducted on DLC, there are no reported results for coating DLC on carbon/carbon composites. Therefore, processing parameters as well as properties must be established for the proposed system. 


\section{Importance to LANL's Science and Technology Base and National R\&D Needs}

The processing technology and chemical-vapor infiltration (CVI) techniques used in this project continue to be an important component to defense and energy technology programs at the Laboratory. Numerous applications exist for related CVI technology in core DOE missions. Advanced composites such as the carbon/carbon materials with controlled porosity have applications in national security, energy and environmental technologies, and science and technology. These and related materials are currently being explored for membrane materials for energy-efficient gas separations and filtration. Composites as light-weight, high-temperature materials are being explored for advanced energy efficient engines and have applications in weapons systems and missile components. The research conducted within this project has led to an improved understanding of microstructure/property relationships for advance composite materials.

\section{Scientific Approach and Accomplishments}

We have investigated the use of a LANL-developed process for the fabrication of carbon-fiber-reinforced composites with a pyrolytic carbon matrix. The biocompatibility of pyrolytic carbon produced by chemical vapor deposition is well established. It has been used for artificial heart valves for over 25 years. We have entered into collaboration with Ascension Orthopedics of Austin, Texas. Ascension is developing a carbon-based metacarpophalangeal joint (Figure 1). Their approach is to use technology developed for the fabrication of artificial heart valves. This process involves coating a graphite substrate with CVD isotropic carbon. The isotropic carbon increases the strength of the graphite and provides a good wear surface. While this technology results in a carbon material suitable for finger joints, it will not be adequate for larger load-bearing joints such as hips and knees. The high strength of these carbon materials comes from the CVD carbon coating. These coatings can only be applied to thicknesses on the order of 30 mils. For large diameter parts, 30-mil coatings will not enhance the strength of graphite enough to meet requirements. Thus carbon-fiber-reinforced composites offer a method of producing a higher strength carbon. The goal of this effort was to evaluate these materials for this application. We have investigated processing issues, fiber preform structure and architecture, strength and biocompatibility. The application of diamond-like carbon on these materials has also been investigated. The following summarizes the results this investigation.

Composites were fabricated using an electromagnetic induction heating process developed at LANL. An advantage in using electromagnetic energy in CVI is the ability to 
couple energy directly into the substrate with the possibility of heating the substrate volumetrically. Volumetric heating, together with heat losses at the surfaces due to radiation and convection, gives rise to "inverted" thermal gradients. With the internal region of the substrate hot, cool reactant gases penetrate inward prior to the onset of the deposition reaction. Consequently, deposition can occur from the inside out. Inside-out densification minimizes premature pore closure in outer regions, resulting in a spatially uniform composite. Alternatively it provides a means of grading.porosity such that porosity at the surface for bone in-growth is possible. Decreases in processing time are also possible. A cold-wall reactor will minimize unwanted deposition on the walls and fixtures and reduce gas-phase nucleation thereby saving on reactant costs, minimizing waste production, and allowing for higher pressure processing.

The concept for the production of inverted gradients is illustrated in Figure 2. Ordinary radiant heating results in rapid attenuation of the radiation at the surface. In the microwave and $R F$ regions of the spectrum the penetration of the radiation into the part increases. The magnetic intensity of the electromagnetic wave decays exponentially with increasing distance into the part. For induction heating the current induced falls off in a similar manner and is characterized as a skin or current depth given by the following relation:

$$
\delta=(1 / \pi f \mu \sigma)^{1 / 2}
$$

where:

$\mathrm{f}$ is the frequency $\mathrm{Hz}$,

$\mu$ is the magnetic permeability $\mathrm{H} / \mathrm{m}$, and

$\sigma$ is the electrical conductivity $\Omega^{-1} \mathrm{~m}^{-1}$.

Thus the degree of volumetric heating depends on the frequency and electrical conductivity of the material. For a carbon fiber preform, the electrical conductivity is estimated at $25,000 \Omega^{-1} \mathrm{~m}^{-1}(3)$. Using this value the variation in current depth with frequency is shown in Figure 3. As illustrated in Figure 2, the power distribution penetrates the interior resulting in volumetric heating. The temperature distribution falls off at the surface due to radiative and convective losses leading to an inverted temperature gradient. For the deposition of carbon from methane, a difference in temperature of $200^{\circ} \mathrm{C}$ can reduce the 
deposition rate by a factor of 150 near the exterior surface of the preform, resulting in deposition from the inside out.

A reactor consisting of a simple induction coil operated at $50 \mathrm{kHz}$ is illustrated in Figure 4. Samples were heated without insulation to temperatures ranging from 1100 to $1400^{\circ} \mathrm{C}$. These samples were cut into cylinders approximately 1 inch in diameter by 3 inches in length. The matrix was deposited by pyrolysis of methane at pressures ranging from 100 to 300 torr, with a flow rate of $200 \mathrm{sccm}$. Temperature gradients were monitored with thermocouples inserted in the preform at various radial positions.

Three-dimensional (3-D) carbon-fiber preforms, consisting of an $80 \%$ eightharness satin fabric with $20 \%$ chopped fiber needled in the $\mathrm{z}$ direction, were used. This structure provides a 3-D, orthogonal fiber reinforcement and quasi-isotropic properties. The fiber was fully graphitized with $2.2 \mathrm{GPa}$ strength and a $700 \mathrm{GPa}$ elastic modulus. For the process conditions of $1330^{\circ} \mathrm{C}, 100$ torr and $200 \mathrm{sccm}$ of methane, the evolution of the temperature gradient from the centerline to the surface was monitored. Figure 5 shows this variation with time. The initial increase in $\Delta \mathrm{T}$ is thought to be caused by preferential deposition on the interior of the preform, resulting in stronger coupling of the electromagnetic radiation to the center of the preform. The process is initially selfpropagating and the total absorbed power required continually decreases. Eventually, as deposition near the exterior occurs, the temperature gradient decreases. Materials have been processed to densities in the range of $1.7 \mathrm{~g} / \mathrm{cc}$ in as little as 30 hours. Figure 6 shows a typical dense composite by this process.

Results of flexure tests yielded strengths of $120 \mathrm{MPa}$ and a flexure modulus of 30 GPa. This is essentially what should be expected for this fiber architecture. The strength is two to three times that of bone with an elastic modulus similar to bone. With proper design of a device it is anticipated that this material will meet performance requirements in terms of strength and eliminate effects of stress shielding. For the smaller finger joints using existing device designs, a higher strength stem material is desirable. This is a consequence of the small diameters required for insertion into existing bone.

An alternative fiber structure was investigated and is illustrated in Figure 7a. This material consisted of a core of unidirectional carbon fiber tow with 40,000 filaments and an outer layer of carbon fiber braid. The unidirectional tow provides high strength in the axial direction while the braid provides resistance against buckling, a lower modulus at the bone composite interface, and porosity for bone in-growth. Flexure strength for this material was measured at $360 \mathrm{MPa}$, more than adequate for use in an MP joint. Composite heads made of 3-D fiber preforms were joined to these stems by direct chemical vapor bonding. 
Figure $7 \mathrm{~b}$ shows a prototype joint demonstrating the feasibility of fabricating a device by this method. Microstructures of this material are shown in Figure 8. High densities are clearly achieved for the core materials with an estimated strength of $700 \mathrm{MPa}$. Spaces between the fiber tows within the braid provide adequate porosity for bone in-growth.

A process for the deposition of diamond-like carbon onto articulating surfaces of carbon MP joints and composite material was also developed. The system, illustrated in Figure 9, consisted of a high vacuum chamber equipped with a $13.56 \mathrm{MHz} \mathrm{RF}$ power supply and matching network. The part was directly fixed to the powered lead, and the chamber was grounded. With this arrangement the part itself is the cathode of a capacitively coupled plasma discharge. Methane gas was introduced into the chamber and a discharge formed around the part. Carbon species generated in the plasma are accelerated over a 400-volt self bias to the substrate where they deposit and form a hard DLC film. Figure 10 shows the micro-Raman spectra for these coatings typical of DLC. Welladhered, smooth conformal coatings were formed on all parts of the articulating surface of the MP joint for both cup and ball components.

Samples were evaluated for biocompatibilty at Tulane University and no adverse cellular reaction was detected after a 12-week in-vitro test. Wear testing of DLC coated materials by Ascension is planned. We are now evaluating designs for an artificial hip using finite-element analysis, and a process is being developed for the fabrication of a fullscale artificial hip joint.

\section{Publications}

1. Devlin D., Carroll D., Barbero R., Klawitter J., Strzepa P., Ogilive W/. "Carbon Based Prosthetic Devices," Proceedings of International Mechanical Engineering Congress, Advances in Bioengineering ASME, BED Vol. 36, p 265 (1997).

2. Devlin D.J., Barbero R.S., Siebein K.N., "Radio Frequency Assisted Chemical Vapor Infiltration," Proc. Electrochem. Soc. 96-5, 571-578 (1996).

3. Devlin D., Cowie J.,Carroll D., Rivero D.,"Systems Approach to Improved Orthopedic Prosthetic Devices," Proceedings of International Mechanical Engineering Congress. Advances in Bioengineering, Vol. 31, p 31 (1995). 


\section{References}

[1]. E. Fitzer, W. Hütter, L. Claes, and L. Kinzl, "Torsional Strength of Carbon Fibre Reinforced Composites for the Application as Internal Bone Plates," Carbon Vol. 18, pp. 383-387 (1980).

[2]. B. Kummer, "Biomechanics of Bone: Mechanical Properties, Functional Structure, Functional Adaptation," Biomechanics, Y. Fung, N. Perrone, and M. Anliker, Eds., pp. 237-269.

[3]. J. Atkinson, G. Isaac, D. Dowson, and B. Wroblewski, "Laboratory Wear Tests and Clinical Observations of the Penetration of Femoral Heads Into Acetabular Cups in Total Replacement Hip joints. III. The Measurement of Internal Volume Changes in Explanted Charnley Sockets After 2-6 Years In Vivo and the Determinations of Wear Factors," Wear Vol 104, pp. 225-244 (1985).

[4]. J. Angus, P. Koidl, and S. Dormitz, in Plasma Deposited Thin Films, J. Mort and F. Jansen, Eds., CRC Press, Boca Raton, FL, p. 89 (1986).

[5]. A. Lettington, "Applications of Diamond-Like (Hard Carbon) Films," Diamond and Diamond-Like Films and Coatings, R. Clausing et al., eds., Plenum Press, New York, pp. 481-498 (1991).

[6]. D. Adams and D. Williams, "The Response of Bone to Carbon/carbon Composites," Biomater.Vol. 5, pp. 59-64 (March 1994).

[7]. J. Moran, "Materials for Ligament Replacement," SAMPE J., pp. 10-13 (MayJune,1985). 


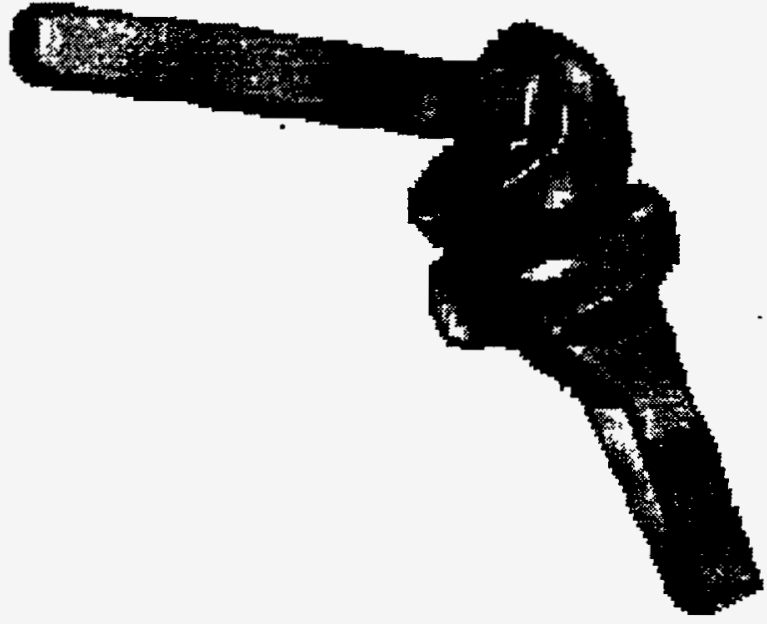

Figure 1. Ascension Orthopedics pyrolytic carbon coated MP joint.

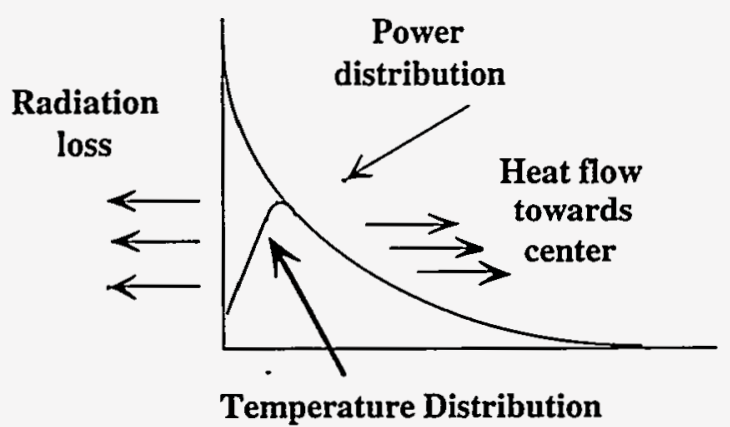

Figure 2. The effect of volumetric heating on the temperature distribution.

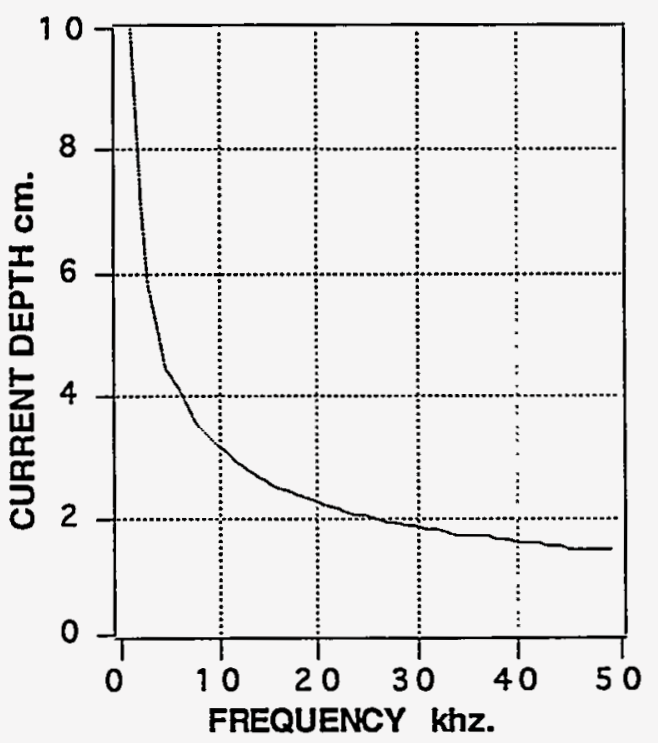

Figure 3. Variation in skin depth as a function of frequency for a carbon/carbon composite. 


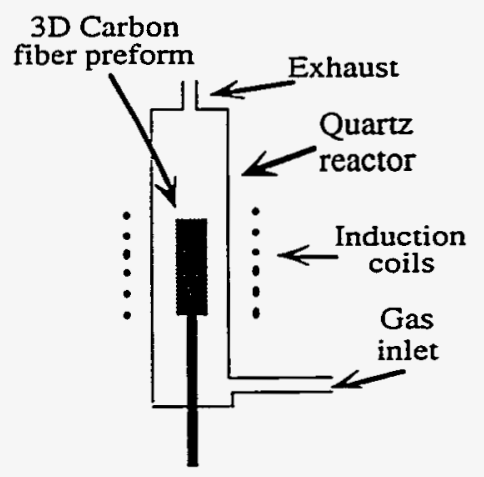

Figure 4. Schematic of the rf-heated CVI reactor.

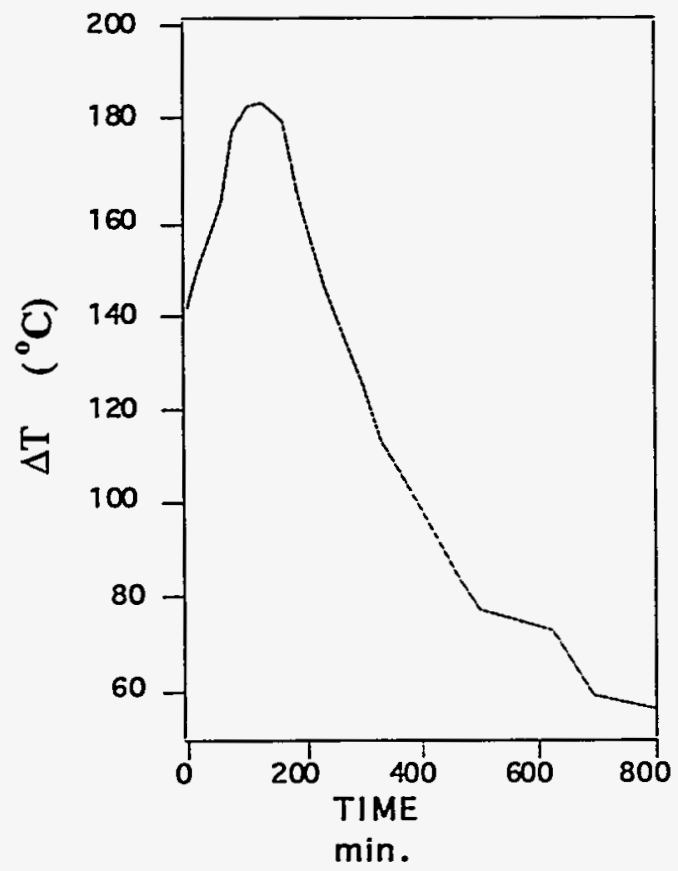

Figure 5. Evolution of temperature gradients with time.

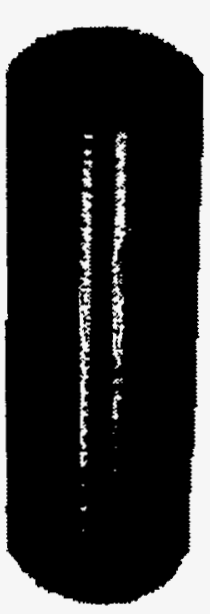

Figure 6. Dense carbon/carbon composite. 

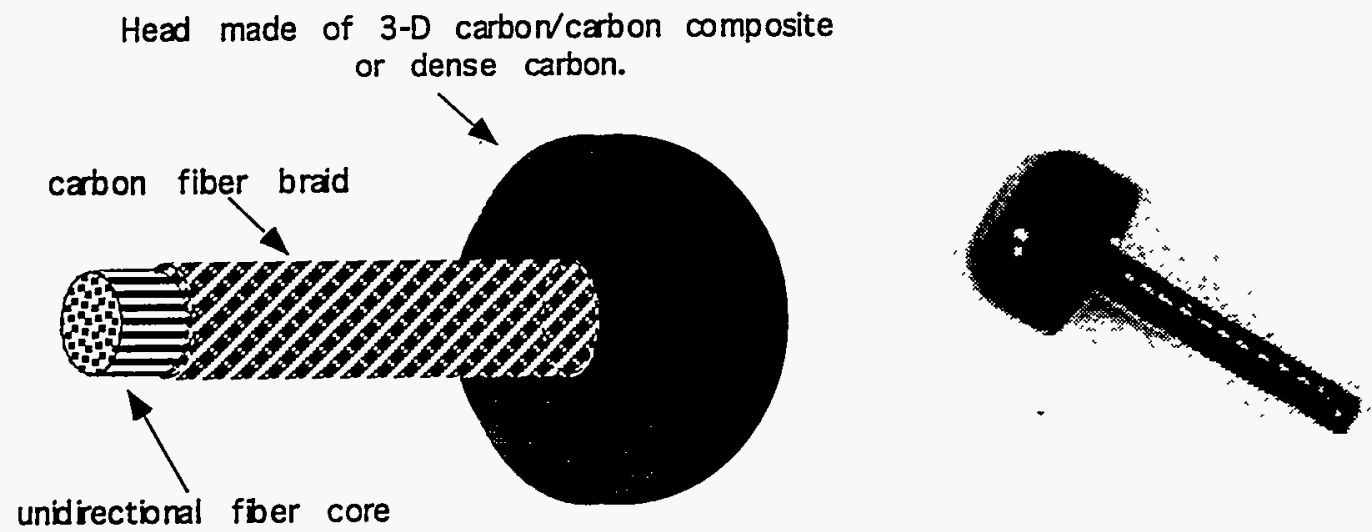

(a)

(b)

Figure 7. (a) drawing of prototype MP joint illustrating unidirectional fiber core with outer fiber braid. (b) prototype MP joint.
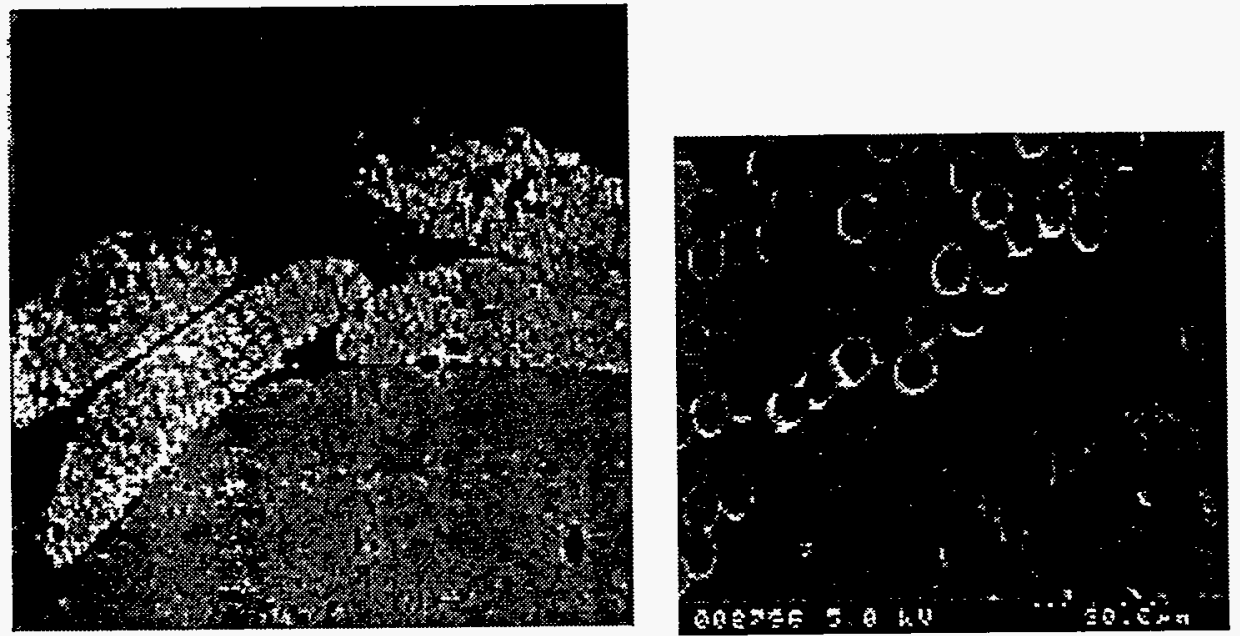

Figure 8. Micrographs of cross section of dense material showing the core and braid and outer braid structure. 


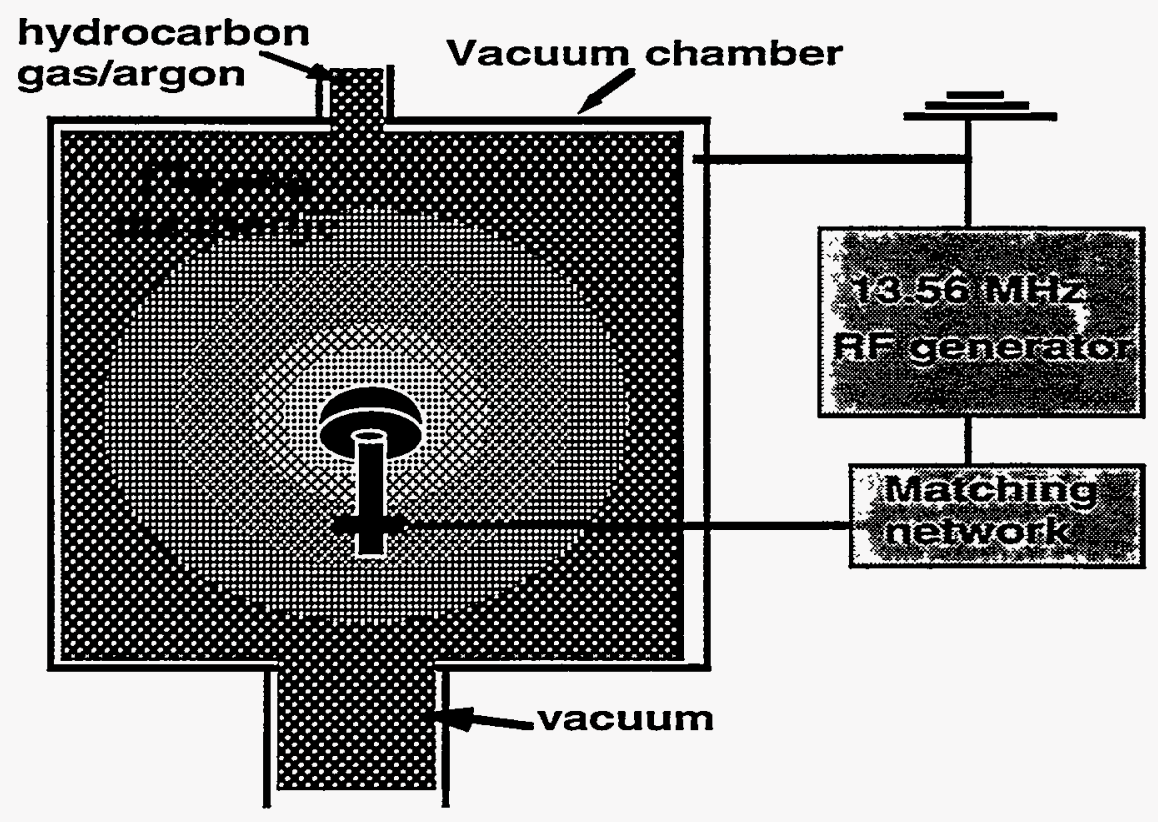

Figure 9. Schematic of the plasma-assisted CVD reactor used to deposit DLC films on MP joints.

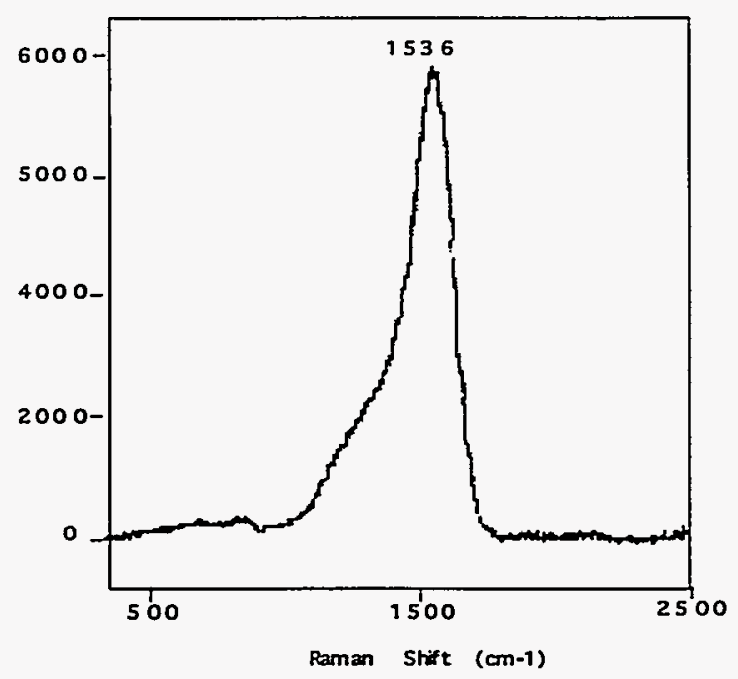

Figure 10. Micro-Raman spectra of the coatings on MP joint head. The spectra is typical of hard DLC coatings. 